\title{
Insertion of a foldable hydrophobic IOL through the trabeculectomy fistula in cases with Microincision cataract surgery combined with trabeculectomy
}

\author{
Tanuj Dada, Rajamani Muralidhar and Harinder S Sethi*
}

Address: Centre for Ophthalmic Sciences, All India Institute of Medical Sciences, New Delhi 110029, India

Email: Tanuj Dada - tanujdada@hotmail.com; Rajamani Muralidhar - muralidharr@yahoo.com; Harinder S Sethi* - sethi2211@yahoo.com

* Corresponding author

Published: 19 March 2006

BMC Ophthalmology 2006, 6:14 doi:10.1186/147|-2415-6-14

This article is available from: http://www.biomedcentral.com//47I-24I5/6/14

(c) 2006 Dada et al; licensee BioMed Central Ltd.

This is an Open Access article distributed under the terms of the Creative Commons Attribution License (http://creativecommons.org/licenses/by/2.0), which permits unrestricted use, distribution, and reproduction in any medium, provided the original work is properly cited.

\begin{abstract}
Background: The use of conventional foldable hydrophobic intraocular lenses (IOLs) in microincision cataract surgery (MICS) currently requires wound enlargement. We describe a combined surgical technique of MICS and trabeculectomy with insertion of a foldable IOL through the trabeculectomy fistula.
\end{abstract}

Methods: After completion of MICS through two side port incisions, a $3.2 \mathrm{~mm}$ keratome is used to enter the anterior chamber under the previously outlined scleral flap. An Acrysof multi piece IOL (Alcon labs, Fort Worth, Tx) is inserted into the capsular bag through this incision. The scleral flap is then elevated and a $2 \times 2 \mathrm{~mm}$ fistula made with a Kelly's punch. The scleral flap and conjunctival closure is performed as usual.

Results: Five patients with primary open angle glaucoma with a visually significant cataract underwent the above mentioned procedure. An IOL was implated in the capsular bag in all cases with no intraperative complications. After surgery, all patients obtained a best corrected visual acuity of 20/20, IOL was well centered at 4 weeks follow up. The mean IOP (without any antiglaucoma medication) was $13.2+2.4 \mathrm{~mm} \mathrm{Hg}$ at 12 weeks with a well formed diffuse filtering bleb in all the cases.

Conclusion: The technique of combining MICS with trabeculectomy and insertion of a foldable $\mathrm{IOL}$ through the trabeculectomy fistula is a feasible and valuable technique for cases which require combined cataract and glaucoma surgery.

\section{Background}

The combined surgical technique of phacotrabeculectomy has become a common technique for management of eyes with co-existent cataract and glaucoma [1,2]. Phacotrabeculectomy is either done as a single site surgery with both phacoemulsification and trabeculectomy performed from the same site or more commonly as a two-site surgery. Separating the two incisions may decrease the inflamma- tion and subsequent fibrosis induced by the surgery leading to a better survival of the filtering bleb [2-4].

Microincision cataract surgery (MICS) or Phakonit (implying phacoemulsification performed with a needle) is a recently introduced bimanual technique that permits phacoemulsification via sub $1-1.2 \mathrm{~mm}$ incisions. The basic principle is to separate the irrigation from the 
phacoemulsification handpiece and use an irrigating chopper to maintain the anterior chamber. The advantages of MICS include an anastigmatic, safer, closed chamber surgery via smaller incisions and rapid visual restoration with minimal post operative inflammation [2,5-11]. We introduce a new technique of combining MICS with trabeculectomy and insertion of a foldable IOL through the trabeculectomy fistula.

\section{Methods}

We performed MICS with trabeculectomy and insertion of a foldable IOL through the trabeculectomy fistula in 5 eyes of 5 patients in which combined cataract and glaucoma surgery was indicated due to significant cataract and medically uncontrolled IOP. Surgery was performed under peribulbar anesthesia. The eye was cleaned and draped and a superior rectus bridle suture was inserted. A limbus-based conjunctival flap was made, starting $10 \mathrm{~mm}$ behind the superior limbus. The conjunctiva was dissected to the limbus and a $4 \times 4 \mathrm{~mm}$ rectangular scleral flap was fashioned in the superonasal quadrant. The flap was undermined and dissected to clear cornea using a steel crescent knife. The conjunctiva was then reposited back and cataract surgery was started. Two $1.2 \mathrm{~mm}$ clearcorneal side port incisions were made at 10 o'clock and 2 o'clock with a MVR knife. The anterior capsular staining with 0.1 cc trypan blue $(0.06 \%)$ under air bubble was done in cases with poor or no red reflex. The anterior chamber was filled with $1 \%$ sodium hyaluronate. A bent 26G needle was used to perform capsulohexis and gentle hydrodissection was then performed. An irrigating chopper was inserted via the 2 o'clock port and then a sleeveless $20 \mathrm{G}$ phaco tip was inserted through the 10 o'clock port. The infusion was maintained with two bottles of balanced salt solution connected together via a "Y" shaped tubing to increase the infusion (TURP tubing-trans uretheral resection of prostrate tubing) raised to $140 \mathrm{~cm}$. Bimanual phacoemulsification (Figure 1) using stop and chop nucleotomy technique with the WhiteStar Sovereign phacoemulsification system (Advanced Medical Optics, Inc) was performed. The cortical matter was removed with bimanual irrigation aspiration system. After cortical removal, $1 \%$ sodium hyaluronate was injected into the anterior chamber. A $3.2 \mathrm{~mm}$ keratome was used to enter the anterior chamber under the previously outlined scleral flap. An Acrysof multi piece IOL (Alcon labs, Fort Worth, $\mathrm{Tx}$ ) was inserted into the capsular bag through this incision using a holder and folder (Figure 2). The scleral flap was then elevated and a $2 \times 2 \mathrm{~mm}$ fistula made with a Kelly's punch (Figure 3 ). An iridectomy was performed and the scleral flap was closed with two 10-0 monofilament sutures. Viscoelastic was removed from the anterior chamber and the capsular bag using bimanual irrigation aspiration via the two side ports. The side ports were hydrated and the conjunctiva closed with a running 8-0

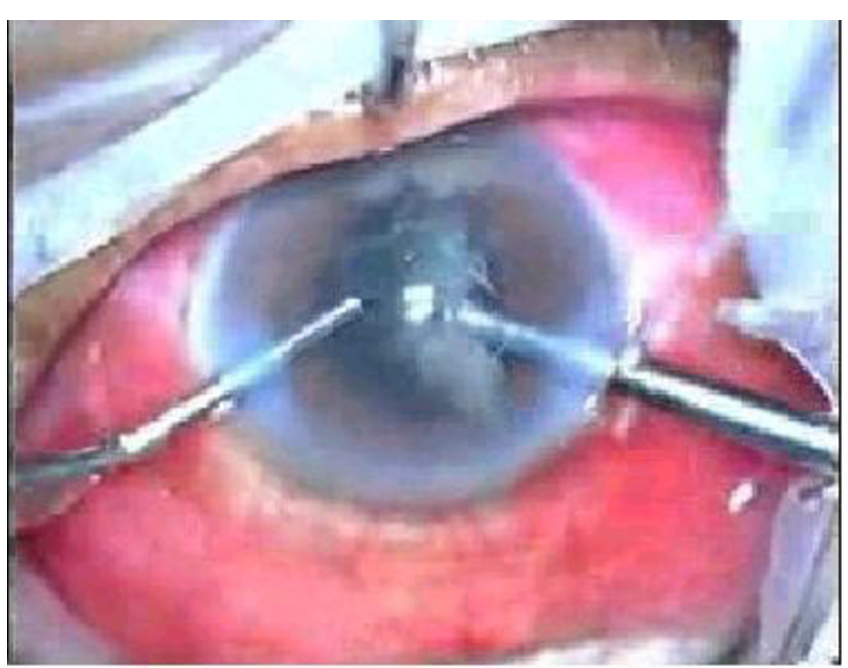

Figure I

Bimanual microincision phacoemulsification being performed.

vicryl suture. A subconjunctival injection of $0.1 \mathrm{cc}$ dexamethasone was given and all patients received $1 \%$ prednisolone acetate eye drops (6 times/day), 0.3\% ciprofloxacin eye drops (3 times/day) and 1\% tropicamide (HS) in the post operative period.

\section{Results}

Five patients with primary open-angle glaucoma with a visually significant cataract were operated with the above mentioned technique (Table 1). Pre-operatively all patients had an IOP $>21 \mathrm{mmHg}$ on two or more topical anti-glaucoma medications. After surgery, visual acuity on the first post operative day ranged from $20 / 20$ to $20 / 40$. All patients obtained a best corrected visual acuity of 20/

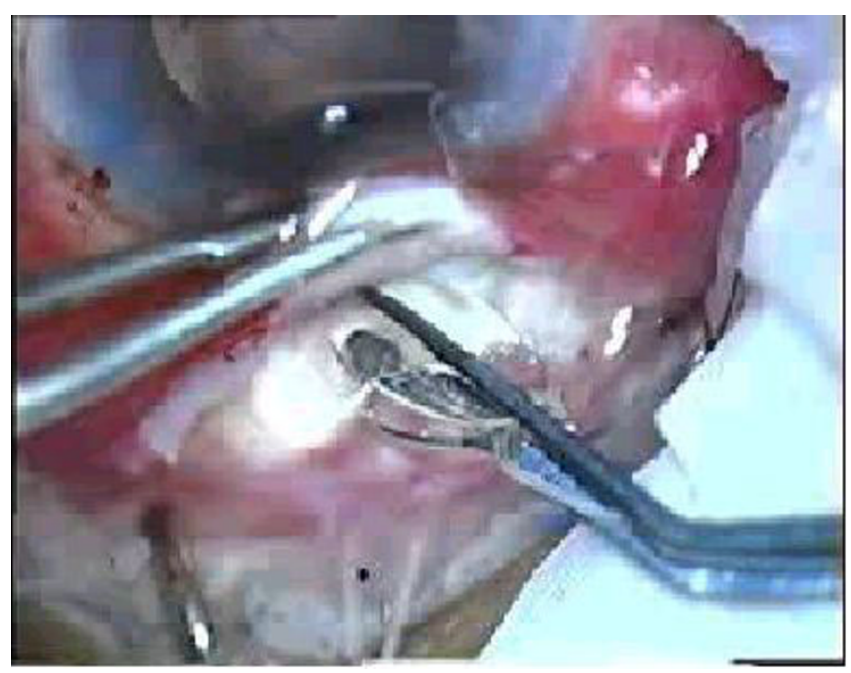

Figure 2

Acrysof multipiece piece IOL being introduced under the scleral flap. 


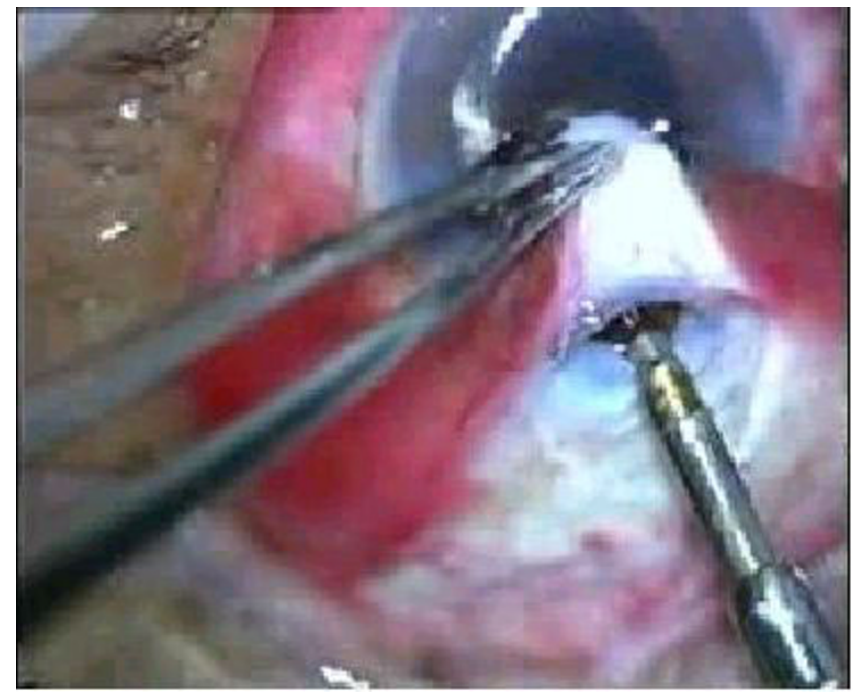

Figure 3

Trabeculectomy ostium being cut with the Kelly's descemet punch.

20 at 4 weeks follow up. The mean IOP (without any antiglaucoma medication) was $12.4+2.6 \mathrm{~mm} \mathrm{Hg}$ at 4 weeks and $13.2+2.4 \mathrm{~mm} \mathrm{Hg}$ at 12 weeks with a wellformed diffuse filtering bleb in all the cases.

\section{Discussion}

Combined surgery involving phacoemulsification and trabeculectomy has a reduced success rate compared to trabeculectomy alone [12]. This may be related to additional inflammation induced during cataract extraction [13]. Two-site surgery, separating the phacoemulsification and the trabeculectomy sites has theoretical advantages of reducing inflammation at the site of the filter and thereby may decrease the stimulus for the subsequent fibroblastic response [2-4]. Standard two site phacotrabeculectomy requires two large incisions, one for the cataract surgery and the other as the ostium under the scleral flap. In addition, the surgeon needs to adjust his position intraoperatively along with that of his assistants and equipments (i.e superior for trabeculectomy and temporal for phacoemulsification).
MICS/Phakonit offers the dual advantage of performing a bimanual closed chamber surgery and removing the cataract via an incision which is one-third the size of a routine phacoemulsification incision (1-1.2 $\mathrm{mm}$ versus a standard $3.2 \mathrm{~mm}$ incision) [6-8]. These ultra small incisions induce less inflammation $[2,8-11]$ which is a significant advantage when this surgery is combined with a trabeculectomy. A reduction in post-operative inflammation is likely to reduce the risk of fibrosis and filter failure.

This technique offers the additional advantage of implantation of a standard hydrophobic acrylic IOLs with reduced risk of posterior capsule opacification [14] through the ostium of the trabeculectomy incision. One does not have to enlarge the side port incisions for introducing the IOL. Although new ultrathin IOLs (such as the ThinOptx rollable IOL) have been implanted after MICS, further investigation is required before they are adopted as a standard procedure in cataract surgery [15].

The combined two site surgery by this technique can be performed with surgeon sitting superiorly i.e without the need to change position intraoperatively. This considerably reduces the surgical time. This technique maintains the integrity of the small incisions used for cataract surgery and does not increase the inflammation that can be caused by a larger wound and additional manipulation. We believe thus that the combination of MICS with trabeculectomy is a valuable technique for management of eyes with co-existent cataract and glaucoma.

\section{Conclusion}

The technique of combining MICS with trabeculectomy and insertion of a foldable IOL through the trabeculectomy fistula is a feasible and valuable technique for cases which require combined cataract and glaucoma surgery.

\section{Abbreviations}

MICS : Micro-incision cataract surgery

IOL : Intraocular lens

Table I

\begin{tabular}{|c|c|c|c|c|c|c|}
\hline Case No & Pre-op VA & $\begin{array}{l}\text { Post-Op VA } \\
\text { (4 weeks) }\end{array}$ & $\begin{array}{l}\text { Pre-op Mean IOP } \\
\text { (of diurnal curve) }\end{array}$ & $\begin{array}{l}\text { Post-op Mean IOP } \\
\text { (12 weeks) }\end{array}$ & $\begin{array}{l}\text { Pre-op Antiglaucoma } \\
\text { medications }\end{array}$ & $\begin{array}{c}\text { Post-op } \\
\text { Antiglaucoma } \\
\text { medications }\end{array}$ \\
\hline I & $20 / 200$ & $20 / 20$ & 24.5 & 15.6 & Timolol, Latanoprost & Nil \\
\hline 2 & $20 / 120$ & $20 / 20$ & 27.8 & 11.0 & Timolol, Pilocarpine, Brimonidine & Nil \\
\hline 3 & $20 / 60$ & $20 / 15$ & 25.6 & 12.0 & Latanoprost, Brimonidine & Nil \\
\hline 4 & $20 / 120$ & $20 / 20$ & 30.4 & 16.0 & Timolol, Bimatoprost, Brimonidine & Nil \\
\hline 5 & $20 / 80$ & $20 / 15$ & 24 & 11.4 & Timolol, Brimonidine, Dorzolamide & Nil \\
\hline
\end{tabular}




\section{Competing interests}

The author(s) declare that they have no competing interests.

\section{Authors' contributions}

TD : Conceived the idea of above technique, and performed the surgeries.

\section{RM : Helped in documentation of cases}

HSS : Compiled the data and helped in the preparation of the manuscript

All authors read and approved the final manuscript.

\section{Acknowledgements}

Written consent was obtained from the patient or their relative for publication of study.

\section{References}

I. Friedman DS, Jampel HD, Lubomski LH, Kempen JH, Quigley H, Congdon N, Verbin HL, Robinson KA, Bass EB: Surgical Strategies for Coexisting Glaucoma and Cataract. Ophthalmology 2002, I09(10): 1902-1913.

2. Verges C, Jorge C, Cosme L: Surgical strategies in patients with cataract and glaucoma. In Current Opinion in Ophthalmology (C) 2005 Volume 16. Issue I Lippincott Williams \& Wilkins, Inc; 2005:44-52.

3. el Sayyad F, Helal M, el-Maghraby A, Khalil M, el-Hamzawey H: Onesite versus two-sites phacotrabeculectomy: a randomized study. J Cataract Refract Surg 1999, 25:77-82.

4. Wyse T, Meyer M, Ruderman JM, Krupin T, Talluto D, Hernandez R, Rosenberg LF: Combined trabeculectomy and phacoemulsification: a one-site vs two-site approach. Am J Ophthalmol 1998, I 25:334-339.

5. Aggarwal S, Sundaram, Asha B: Laser Sclerotomy, Laser Phakonit, IOL Implantation. Edited by: Agarwal S, Agarwal A, Agarwal A. Phacoemulsification. New Delhi: Jaypee Brothers; 2004:609-6I2.

6. Agarwal A, Agarwal A, Agarwal S: Phakonit. Volume I. Edited by: Agarwal S, Agarwal A, Agarwal A. Phacoemulsification. New Delhi: Jaypee Brothers; 2004:3 18-329.

7. Agarwal A, Agarwal A, Agarwal S, Narang P, Narang S: Phakonit: phacoemulsification through a $0.9 \mathrm{~mm}$ corneal incision. J Cataract Refract Surg 2001, 27:1548-1552.

8. Tsuneoka H, Shiba T, Talcehashi Y: Ultrasonic phacoemulsification using a $1.4 \mathrm{~mm}$ incision. J Cataract Refract Surg 2002, 28:8।-86.

9. Verges C, Cazal J, Cipres MC: Endothelial cell density and corneal thickness in cataract surgery comparing continuous vs micropulsed ultrasound. Cornea in press.

10. Soscia W, Howard JG, Olson RJ: Microphacoemulsification with Whitestar: a wound temperature study. J Cataract Refrac Surg 2002, 28: 1044-1046.

II. Fine $H$, Packer $M$, Hoffman RS: Power modulation in new phacoemulsification technology: improved outcomes. J Cataract Refract Surg 2004, 30:1014-1019.

12. Caporossi A, Casprini F, Tosi GM, Balestrazzi A: Long-term results of combined phacoemulsification, intraocular lens implantation, and trabeculectomy. J Cataract Refract Surg 1999, 25: I 64 I-5.

13. Siriwardena D, Kotecha A, Minassian D, Dart JK, Khaw PT: Anterior chamber flare after trabeculectomy and after phacoemulsification. BrJ Ophthalmol 2000, 84(9): I056-7.

14. Hollick $E$, Spalton $D$, Ursell $P$ : Lens epithelial cell regression on the posterior capsule with different intraocular lens materials. Br J Ophthalmol 1998, 82: I I82-II88.

15. Dogru M, Omoto M, Fujishima H, Yagi Y, Tsubota K: Early visual results with rollable ThinOptx intraocular lens. J Cat Refract Surg 2004, 30:558-565.

\section{Pre-publication history}

The pre-publication history for this paper can be accessed here:

http://www.biomedcentral.com/1471-2415/6/14/prepub
Publish with Biomed Central and every scientist can read your work free of charge

"BioMed Central will be the most significant development for disseminating the results of biomedical research in our lifetime. "

Sir Paul Nurse, Cancer Research UK

Your research papers will be:

- available free of charge to the entire biomedical community

- peer reviewed and published immediately upon acceptance

- cited in PubMed and archived on PubMed Central

- yours - you keep the copyright
BioMedcentral 